Dossier

\title{
Da divisão sexual do trabalho à naturalização da opressão: um estudo acerca das obras de Engels e Clastres
}

From the sexual division of labor to the naturalization of oppression: a study on the works of Engels and Clastres Desde la división sexual del trabajo hasta la naturalización de la opresión: un estudio sobre los trabajos de Engels y Clastres

\begin{abstract}
Mariana Silveira dos Santos Rosa| Instituto Federal Catarinense - BRASIL |
Mestranda do Programa de Pós-graduação em Educação do Instituto Federal Catarinense, na linha de pesquisa Educação e Inclusão. Graduada em Pedagogia pela Universidade Federal de Santa Catarina (UFSC). Professora auxiliar de Educação Infantil, na rede municipal de ensino de Florianópolis (SC) desde 2014.

E-mail:marianassrosa@gmail.com
\end{abstract}

RESUMO: Este artigo pretende apresentar um estudo acerca de diferentes abordagens em relação à divisão sexual do trabalho. Para tanto tomou por base textos clássicos do pensamento social, de modo a estabelecer uma comparação entre dois estudos antropológicos, nos quais a divisão sexual do trabalho é vista como base das relações sociais de determinadas sociedades. Optou-se por trabalhar com os livros A Sociedade contra Estado, de Pierre Clastres, e "A Origem da Família, da Propriedade Privada e do Estado", de Friedrich Engels, no qual a divisão do trabalho por sexo é apresentada como aspecto socialmente construído no processo de desenvolvimento do capitalismo. Buscou-se, deste modo, mapear alguns elementos que possam vir a auxiliar a compreensão da problemática relacionada à divisão sexual do trabalho.

Palavras-chave: Divisão sexual do trabalho; Estado; Friedrich Engels; Pierre Clastres.

ABSTRACT: This article intends to present a study on different approaches to the sexual division of work. This has been based on classical texts of social thought, in order to establish a comparison between two anthropological studies, in which the sexual division of work is seen as the basis of the social relationships of certain societies. It was decided to work with the books "The Society against State", by Pierre Clastres, and "The Origin of the Family, Private Property and the State", by Friedrich Engels, in which the division of work by sex is presented as a socially constructed aspect in the process of development of capitalism. Thus, we sought to map some elements that may help the understanding of the problem related to the sexual division of work.

Keywords: Sexual division of work; State; Friedrich Engels; Pierre Clastres. 


\section{INTRODUÇÃO}

Em 2018 o IBGE apresentou o material Estatísticas de Gênero: indicadores sociais das mulheres do Brasil. A partir deste material é possível obter uma noção mais assertiva e coerente em relação à divisão sexual do trabalho no Brasil. Segundo o próprio documento:

Produção de estatísticas de gênero implica, portanto, na desagregação de dados individuais por sexo e outras características, de forma a revelar essas diferenças e desigualdades, e na investigação de questões específicas que afetam um sexo mais do que o outro (IBGE, 2018: 2).

É possível constatar, por exemplo, que em 2016 as mulheres dedicavam mais de 18 horas semanais aos afazeres domésticos, incluindo os cuidados com pessoas de suas casas, enquanto os homens dedicavam cerca de dez horas a estas mesmas tarefas. Ou seja, as mulheres dedicam muito mais tempo de suas vidas ao trabalho não remunerado do que os homens. Foi possível perceber também uma gritante diferença entre os rendimentos de homens e mulheres, pois enquanto em 2016 o salário médio dos homens era de 2306 reais, no mesmo ano as mulheres recebiam em média 1764 reais. E estes dados se mostram ainda mais cruéis, e até inconsistentes, quando vemos as estatísticas relacionadas à escolarização, tendo em vista que no ano de 2016, mais de $73 \%$ das mulheres na faixa etária indicada para a frequência ao ensino médio estavam matriculadas neste nível de ensino. Em relação aos homens a taxa cai para menos de $64 \%$. No ensino superior as mulheres continuam a se destacar, pois dentre a população com idade acima de 25 anos, as mulheres com nível superior passam dos $23 \%$, enquanto os homens desta faixa etária com nível superior não chegam a $21 \%$. Ou seja, o fato de o salário médio dos homens ser mais alto do que o salário médio das mulheres não está relacionado ao nível de escolarização, pois mesmo sendo mais escolarizadas, as mulheres não recebem os maiores salários.

A análise das estatísticas relacionadas às ocupações reforça este entendimento, pois em 2016, cerca de $62 \%$ dos cargos gerenciais eram ocupados por homens, restando às mulheres $38 \%$ destes cargos. Ou seja, mesmo havendo estatísticas relacionadas à escolarização que mostram as mulheres como mais qualificadas, poucas são escolhidas para assumirem postos de comando, que normalmente são ocupados por homens cujos níveis de escolarização tendem a ser inferiores aos destas mulheres. Em relação às diferenças salariais, por exemplo, pode-se fazer a relação com o tempo destinado ao trabalho não remunerado. Um dos indicadores apresentados no documento do IBGE mostra que, em relação às pessoas ocupadas em trabalho de tempo parcial, existe "um percentual mais elevado de mulheres que trabalha em período parcial, de até 30 horas, quando comparado com os homens" (IBGE, 2018: 4). Diante dos dados apresentados, conclui-se que não é a escolarização que explica o fato de mulheres receberem salários mais baixos ou terem piores condições de trabalho em comparação aos homens, se for levado em consideração, por exemplo, a ideia de que quanto maior a qualificação, maior o salário. Então, qual seria a causa, senão o simples fato de serem mulheres?

Recorrendo ao Dicionário Crítico do Feminismo, encontra-se o conceito de divisão sexual do trabalho como um de seus verbetes, apresentado por Danièle Kergoat como uma noção que "foi primeiramente utilizada pelos etnólogos para designar uma repartição 'complementar' das tarefas entre homens e mulheres nas sociedades que estudavam" (Kergoat, 2009: 67). Ainda segundo a autora:

A divisão sexual do trabalho é a forma de divisão do trabalho social decorrente das relações sociais de sexo; essa forma é historicamente adaptada a cada sociedade. Tem por características a destinação prioritária dos homens à esfera produtiva e das mulheres à esfera reprodutiva (Kergoat, 2009: 67).

O conceito também é discutido e aprofundado por Hirata, quando afirma:

A divisão do trabalho entre os homens e as mulheres é parte integrante da divisão social do trabalho. De um ponto de vista histórico, é possível observar que a estruturação atual da divisão sexual do trabalho (trabalho assalariado/trabalho doméstico, fábrica-escritório/família) surgiu simultaneamente ao capitalismo, e que a relação assalariada não teria podido se estabelecer na ausência do trabalho doméstico (Hirata, 2002: 234).

Esta definição é corroborada pelos indicadores apresentados pelo IBGE em relação ao tempo dedicado a tarefas não remuneradas, como afazeres domésticos e cuidados com pessoas da casa, que são essenciais para a reprodução da força de trabalho.' A divisão das tarefas com base no gênero pode ser explicada a partir de análises

1 Em relação à reprodução da força de trabalho a partir do trabalho doméstico não remunerado, Toledo (2017: 76) esclarece que "o trabalho doméstico é um problema do sistema capitalista de produção, já que tem a ver com o processo de reprodução da força de trabalho. É no lar que essa reprodução se processa". E continua:"Do salário pago pelo capitalista para que a força de trabalho se reproduza, é descontado o trabalho doméstico, aquele realizado no seio da própria família, em especial pela mulher, 
relacionadas à história do desenvolvimento das diferentes sociedades, e à forma como se deram as relações entre os sexos na sociedade capitalista. Em sociedades que têm por base a propriedade privada dos meios de produção, o trabalho realizado por uma parte da população não apenas passou a ocupar uma esfera exclusivamente doméstica, como chegou a deixar de ser entendido como atividade produtiva. Construiu-se histórica e socialmente a percepção de que as atividades realizadas pelas mulheres no ambiente doméstico seriam inferiores ao trabalho realizado pela outra parte desta mesma população.

O presente artigo tem como objetivo discutir como a divisão sexual do trabalho é abordada em textos clássicos do pensamento social. Para tanto, será realizada a comparação de dois estudos antropológicos, nos quais a divisão sexual do trabalho é vista como base das relações sociais de determinadas sociedades. Enquanto para Clastres a divisão das tarefas com base no gênero é naturalizada, por ser aparentemente sustentada nas capacidades biológicas de cada indivíduo, Engels apresenta a divisão do trabalho por sexo como aspecto socialmente construído no processo de desenvolvimento do capitalismo. Com isso entende-se ser possível mapear alguns elementos que auxiliam na compreensão da problemática colocada pela situação atual das mulheres trabalhadoras no Brasil.

\section{A construção social da divisão sexual do trabalho}

Friedrich Engels foi um teórico revolucionário prussiano que, ao lado de Karl Marx, fundou o socialismo científico, mais conhecido como marxismo. Além das diversas obras escritas em parceria ou coautoria com Marx, Engels possui uma extensa produção própria, dentre a qual pode-se destacar o livro "A Origem da Família", da propriedade privada e do Estado, publicado em 1884, e considerado fundamental para o desenvolvimento do materialismo-histórico. Trata-se de um estudo baseado nas pesquisas do antropólogo estadunidense Lewis Morgan, no qual Engels relaciona a origem do Estado com a propriedade privada, ligando esse processo à passagem do matriarcalismo para o patriarcalismo. ${ }^{2}$

Logo no primeiro capítulo, Engels (2002) apresenta três estágios pré-históricos de cultura, tomando como referência a forma como o homem se relaciona com a natureza, e baseando-se na classificação de Morgan em relação à pré-história da humanidade. O estado selvagem é caracterizado como o período no qual a maior parte dos produtos eram coletados da natureza já prontos para serem consumidos ou utilizados, sem quaisquer intervenções do homem sobre eles, embora já existissem produções humanas destinadas a tornar mais fácil a coleta ou o acesso a estes produtos. A barbárie é caracterizada por Engels como o período da domesticação de animais e da maior intervenção humana sobre os produtos da natureza, favorecendo o desenvolvimento da pecuária e da agricultura. Já o período da civilização tem como principal característica o surgimento da indústria, onde o homem aperfeiçoa suas elaborações a partir dos produtos da natureza. Segundo Engels, já na fase inferior da barbárie existia uma divisão sexual do trabalho, como parte da divisão social do trabalho:

O homem vai à guerra, incumbe-se da caça e da pesca, procura as matérias-primas para a alimentação, produz os instrumentos necessários para a consecução de seus fins. A mulher cuida da casa, prepara a comida e confecciona as roupas [...]. Cada um manda em seu domínio (Engels, 2002: 154).

Neste momento a propriedade privada se referia apenas aos instrumentos que cada um produzia e utilizava para realizar suas tarefas. Já tudo o que era feito e utilizado por todos, como, por exemplo, casas, canoas e hortas, tudo pertencia a todos. À medida que a pecuária, a agricultura e as atividades domésticas se desenvolviam, a força de trabalho também se desenvolvia, tornando o homem capaz de produzir para além de suas necessidades e das necessidades de seu povo. Com a possibilidade de produzir mais, facilitando a acumulação de riquezas, foi-se aumentando a jornada diária de trabalho, de modo a garantir a produção de excedentes. Cabe destacar aqui a colocação de Engels em relação à fase média da barbárie:

Passou a ser conveniente conseguir mais força de trabalho, o que se logrou através da guerra; os prisioneiros foram transformados em escravos. Dadas as condições históricas gerais de então, a primeira grande divisão social do trabalho, ao aumentar a produtividade deste, por conseguinte a riqueza, e ao estender o campo da atividade produtora, tinha que trazer consigo - necessariamente - a escravidão. Da primeira grande divisão social do trabalho, nasceu a primeira grande divisão da sociedade em duas classes: senhores e escravos, exploradores e explorados (Engels, 2002: 156).

e pelo qual o capitalista não desembolsa nada". Também segundo Toledo (2017: 78), "o Capital transfere para a família (em especial para a mulher) parte do processo de produção. Assim, reduz o custo de reprodução do trabalhador masculino e de sua força de trabalho, permitindo que o valor seja apropriado para o capital".

2 Lewis Henry Morgan nasceu no ano de 1818, em Aurora, Nova lorque, e morreu no ano de 1881, em Rochester, também Nova lorque. Antropólogo e etnólogo, é considerado um dos fundadores da antropologia moderna, tendo boa parte de sua obra dedicada a reflexões sobre cultura e sociedade. Teve uma atuação política ativa, sendo eleito deputado e senador pelo Partido Republicano, ao qual era filiado. Sua obra A sociedade Primitiva (1877) é considerada um clássico da antropologia, e foi a partir dela que Engels desenvolveu sua pesquisa acerca das origens do Estado. 
Deste modo entende-se que o gado, por exemplo, após ser domesticado, passou a ser utilizado como uma moeda de troca, uma vez que era propriedade do homem que o domesticou. Ou seja, as mercadorias e os escravos obtidos a partir da troca por gado, se tornam automaticamente propriedade do homem que possuía o gado, assim como o excedente da produção obtida pelo trabalho das pessoas escravizadas que passam a pertencer a este homem. Em todo esse processo, a mulher tinha participação apenas na etapa do consumo, passando a ocupar um lugar secundário na hierarquia doméstica. A divisão do trabalho já era a base para a divisão da propriedade entre homem e mulher (cada um era dono dos instrumentos que produzia e utilizava). Mas agora o trabalho doméstico da mulher, mesmo que seja essencial para a sociedade, perde importância e o reconhecimento diante do trabalho produtivo do homem. ${ }^{3}$ Segundo Engels:

Isso demonstra que a emancipação da mulher e sua equiparação ao homem são e continuarão sendo impossíveis, enquanto ela permanece excluída do trabalho produtivo social e confinada ao trabalho doméstico, que é um trabalho privado. A emancipação da mulher só se torna possível quando ela pode participar em grande escala, em escala social, da produção, e quando o trabalho doméstico lhe toma apenas um tempo insignificante (Engels, 2002: 157).

No entanto, mesmo participando em escala social dos processos de produção, a mulher ainda tem o trabaIho doméstico tomando um tempo exorbitante de sua jornada. O trabalho duplicado ainda é uma dura realidade no cotidiano das mulheres, como mostram os dados do IBGE antes apresentados. Ou seja, mesmo incluída no trabalho produtivo social, a ainda grande dedicação do seu tempo ao trabalho doméstico continua tornando impossível que a emancipação da mulher aconteça neste modo de produção da vida. ${ }^{4}$

$\mathrm{Na}$ fase superior da barbárie ocorre uma nova divisão do trabalho, entre artesanato e agricultura. Além disso, a acumulação de riqueza por uns começa a demarcar a divisão da sociedade em classes antagônicas, divisão essa baseada principalmente em uma cruel contradição, pois para que uns enriqueçam, outros devem empobrecer. Desta divisão surge a necessidade de chefes ou controladores que buscavam amenizar as chances de conflitos entre as classes, e o Estado começa a se desenhar na sociedade, começando pelas monarquias.

É importante destacar que a linha traçada por Engels (que se refere às fases da barbárie, e ao início da civilização) são utilizadas para explicar o desenvolvimento da sociedade capitalista e do Estado nesta sociedade. Ou seja, não se trata de uma regra de evolução a ser utilizada na explicação de toda e qualquer sociedade existente, pois tudo depende das organizações sociais e da forma como cada sociedade se relaciona com a natureza para produzir sua existência. Ainda assim, faz-se necessário ressaltar os processos de produção em cada uma destas fases: na fase inferior da barbárie, produzia-se apenas o necessário para suprir as necessidades básicas; na fase média da barbárie, a propriedade do gado provoca um excedente de produção, e gera a primeira divisão social do trabalho; na fase superior da barbárie a divisão do trabalho está pautada na divisão entre agricultura e artesanato.

A civilização consolida as divisões sociais do trabalho e o surgimento dos comerciantes, que, apesar de não se dedicarem à etapa da produção, se tornam sujeitos essenciais para a relação entre dois produtores de materiais diferentes, aproveitando a importância atribuída ao comércio para explorar e acumular riqueza a partir das duas pontas da produção, principalmente nos momentos de crises. A propriedade privada da terra também foi consolidada na etapa da civilização. Engels aponta que:

Com a expansão do comércio, o dinheiro, a usura, a propriedade territorial e a hipoteca, progrediram rapidamente a centralização e a concentração das riquezas nas mãos de uma classe pouco numerosa, o que se fez acompanhar do empobrecimento das massas e do aumento numérico dos pobres (Engels, 2002: 162).

Em suma, pode-se dizer que a divisão social do trabalho teve como consequência a divisão da sociedade em classes, e que a luta destas classes antagônicas teve como consequência a necessidade da criação de um Estado. Engels define o Estado como produto de um determinado grau de desenvolvimento de uma sociedade que "se enredou numa irremediável contradição com ela própria e está dividida por antagonismos irreconciliáveis" (Engels, 2002: 164). O Estado, portanto, se coloca aparentemente acima da sociedade, como se não estivesse diretamente ligado a nenhuma das classes em luta, tendo como principal objetivo a manutenção da ordem e a contenção da luta de classes. Segundo Engels:

\footnotetext{
$\overline{3}$ A definição de trabalho produtivo é assim apresentada por Marx: "Do ponto de vista do processo de trabalho em geral, apresentava-se-nos como produtivo aquele trabalho que se realiza num produto, mais concretamente numa mercadoria. Do ponto de vista do processo capitalista de produção, junta-se uma determinação mais precisa: é produtivo aquele trabalho que valoriza diretamente o capital, o que produz mais-valia" (Marx 2004: 109).

4 Por trabalho duplicado entende-se o conceito de Ricardo Antunes (2009) referente à "duplicidade do ato do trabalho" como a condição da mulher trabalhadora, que se vê obrigada a dividir suas atividades cotidianas entre o trabalho doméstico e o trabalho fora de casa. O autor ainda coloca que a mulher trabalhadora é "duplamente explorada pelo capital: desde logo por exercer, no espaço público, seu trabalho produtivo no âmbito fabril. Mas, no universo da vida privada, ela consome horas decisivas no trabalho doméstico, com o que possibilita (ao mesmo capital) a sua reprodução, nessa esfera de trabalho não diretamente mercantil, em que se criam as condições indispensáveis para a reprodução da força de trabalho de seus maridos, filhos/as e de si própria" (Antunes 2009: 108).
} 
Como o Estado nasceu da necessidade de conter o antagonismo das classes, e como, ao mesmo tempo, nasceu em meio ao conflito delas, é, por regra geral, o Estado da classe mais poderosa, da classe economicamente dominante, classe que, por intermédio dele, se converte também em classe politicamente dominante e adquire novos meios para a repressão e exploração da classe oprimida (Engels, 2002: 166).

Ainda sobre a civilização, é importante destacar que é nesta etapa que se consolida o tipo de família que contribuirá para a constituição do Estado: a família monogâmica, a partir da qual o homem exerce sua supremacia sobre a mulher, não apenas por ser ele o maior acumulador de riquezas, mas também por ser a partir da união monogâmica que a paternidade pode ser confirmada, garantindo o direito de herança apenas aos filhos do chefe daquela família, a nova unidade econômica da sociedade.

Engels aponta também que o surgimento do patriarcado está intrinsecamente relacionado com o "desmoronamento do direito materno" (Engels, 2002: 55). Segundo o autor, o homem, além de proprietário dos instrumentos necessários à produção e dos bens daquela família, "apoderou-se também da direção da casa; a mulher viu-se degradada, convertida em servidora, em escrava da luxúria do homem, em simples instrumento de reprodução" (Engels, 2002: 55). Assim se desenvolve a família patriarcal, caracterizada pela submissão de indivíduos livres e/ou escravizados ao poder paterno de seu chefe.

Entende-se, deste modo, que o processo de exploração da mulher se desenvolve a partir das relações familiares monogâmicas, e que ele está intrinsicamente relacionado ao processo mais amplo de exploração do trabalho de homens e mulheres em diferentes sociedades. Por meio da estruturação da família monogâmica a mulher passou a ser concebida como propriedade do homem, sendo retirada do processo de produção social. Esta relação entre o desenvolvimento econômico das diferentes sociedades e a forma de organização da família deixa claro que a divisão sexual do trabalho é parte indissociável da divisão sexual do trabalho.

\title{
NATURALIZAÇÃO DA DIVISÃO SEXUAL DO TRABALHO
}

Pierre Clastres foi um antropólogo e etnógrafo francês, conhecido principalmente por seus trabalhos na área de Antropologia Política. Em 1974 publicou o livro A Sociedade contra o Estado, que reúne artigos nos quais Clastres desenvolve a ideia de "sociedades contra o Estado" a partir de suas experiências de pesquisas etnográficas com povos indígenas da América do Sul. Segundo esses estudos, o Estado não seria imprescindível por não corresponder às necessidades destes povos. Clastres afirma nesta obra que as "sociedades primitivas são sociedades sem Estado" (Clastres, 1975: 183). Pode-se dizer que é justamente a forma como estas sociedades se organizam em torno do trabalho que faz com que o Estado não seja necessário, pois não há uma divisão de classes, na qual alguns indivíduos têm controle e domínio sobre a produção de outros. Diante disto, Clastres afirma que a "relação política de poder precede e funda a relação econômica de exploração", e ainda que "o poder está antes do trabalho, o econômico é uma derivação do político, a emergência do Estado determina a aparecimento das classes" (Clastres, 1975: 192). Clastres desenvolve esta ideia para se contrapor a outras obras que afirmavam ser impossível pensar ou imaginar uma sociedade sem Estado. Sua perspectiva parece ser contrapor principalmente ao marxismo, que parte do entendimento de que às sociedades que não são divididas em classes antagônicas não se faz necessário o Estado. Segundo Engels,

\begin{abstract}
.... Estado não tem existido eternamente. Houve sociedades que se organizaram sem ele, não tiveram a menor noção do Estado ou de seu poder. Ao chegar a certa fase de desenvolvimento econômico, que estava necessariamente ligado à divisão da sociedade em classes, essa divisão tornou o Estado uma necessidade (Engels, 2002: 167-168).
\end{abstract}

Ou seja, na sociedade capitalista o Estado possui um papel definido de garantir os interesses da classe dominante, mantendo o equilíbrio e evitando as tensões que podem surgir das contradições intrínsecas à sociedade.

De compreensões como a de Clastres surge a noção de que as sociedades primitivas são arcaicas, carentes e incapazes de se desenvolverem, como se a criação do Estado representasse o auge deste desenvolvimento evolutivo e linear. ${ }^{5}$ Sem que sejam levadas em consideração as necessidades da sociedade, ou os entendimentos desta sociedade em relação aos conceitos de capacidade e de desenvolvimento, constroem-se julgamentos a respeito de suas economias baseadas na subsistência, vistas como retrógradas e atrasadas, e à inexistência de mercado se atribui a responsabilidade pela suposta incapacidade produtiva destas sociedades. Cabe destacar, em relação às sociedades primitivas, que a economia de subsistência supre a necessidade destas sociedades. Essa economia de

5 Embora faça críticas ao evolucionismo presente nas Ciências Sociais, o autor não se furta a chamar de "primitivas" e de "arcaicas" as sociedades que está estudando. Para ele, o problema está nas explicações etnocentristas construídas sobre esses processos, sem negar que veja com inferioridade essas sociedades. Ao caracterizar uma sociedade como primitiva, Clastres provoca o entendimento de que está se referindo a uma sociedade incapaz de desenvolver um poder estatal, e até mesmo carente deste poder; ou seja; tal sociedade só estaria completa, ou só deixaria de ser arcaica, com o desenvolvimento do Estado. 
subsistência objetiva a produção do mínimo necessário para a sobrevivência do grupo, permitindo que lhes sobre tempo para atividades consideradas menos produtivas pelas sociedades capitalistas.

Clastres, em alguns momentos, parece exaltar positivamente a ausência de um Estado nas sociedades primitivas. Em outros, contudo, parece entender como positivo o processo de sedentarização que favoreceu a construção dos Estados, chegando a fazer uso da dicotomia selvagens e civilizados para se referir, respectivamente, a sociedades sem Estado e sociedades com Estado. Clastres aponta a sedentarização dos povos como a "consequência mais rica da revolução neolítica, pelo fato de ter permitido, pela concentração de uma população estabilizada, a formação das cidades e, para além disso, dos aparelhos estatais" (Clastres, 1975: 194). Além disso, o autor parece destacar a relação entre nomadismo e sedentarização como determinante para a criação de um Estado, deixando claro que a origem do Estado não está em uma

[...] hipotética modificação das relações de produção na sociedade primitiva, modificação essa que, dividindo pouco a pouco a sociedade em ricos e pobres, exploradores e explorados, conduziria mecanicamente à instauração de um órgão de exercício do poder dos primeiros sobre os segundos, ao aparecimento do Estado (Clastres, 1975: 196).

Clastres se equivoca, afinal seria justamente a modificação nas relações de produção que faria com que uma sociedade primitiva passasse pela experiência de ver seu povo dividido em classes antagônicas, sentindo a partir disto a necessidade de criar um órgão regulador para combater as tensões que inevitavelmente viriam a ser provocadas por esta divisão. Esse processo, conforme largamente descrito em diversas obras de Marx e Engels, não se daria de forma mecânica. Por isso cabe à propriedade privada um dos papéis mais importantes na constituição de um Estado, afinal é a partir dela que algumas pessoas conseguem adquirir mais poder do que outras, ampliando o processo de exploração para a produção de riqueza e satisfação de necessidades, tendo por principal instrumento o uso da violência. É a partir da família nuclear monogâmica que surge o direito à propriedade privada, e é a partir do uso da força para garantir o direito à propriedade privada que surge o Estado.

Pode-se considerar como principal acerto de Clastres a consideração de que as raízes da "árvore genealógica do Estado" não se encontram no solo das comunidades primitivas (Clastres, 1975: 198), pois, se deste modo ocorresse, não existiriam ainda nos dias de hoje sociedades que não tem a construção de um Estado entre as suas necessidades. Mesmo existindo nestas sociedades uma figura que, para as sociedades ocidentais capitalistas, é vista como um líder de Estado, como os chefes, ou caciques, ou mesmo pajés, a principal características destas figuras é o fato de eles estarem ao serviço da tribo, e não o contrário; e é justamente essa características que diferencia os líderes das sociedades primitivas dos chefes de Estado das sociedades capitalistas.

Deste modo, realmente é necessário concordar com Clastres quando afirma a "impossibilidade de uma gênese do Estado a partir do interior da sociedade primitiva" (Clastres, 1975: 207). No entanto, também é preciso discordar de sua colocação de que a história dos povos primitivos esteja marcada pela luta contra o Estado. Parafraseando Marx e Engels (2005) ${ }^{6}$, Clastres apresenta a seguinte análise: "A história dos povos que têm uma história é, segundo se diz, a história da luta das classes. A história dos povos sem história é, dir-se-á pelo menos com a mesma verdade, a história da sua luta contra o Estado" (Clastres, 1975: 211). Entende-se que Clastres esteja se referindo aos povos primitivos quando fala em "povos sem história". Sendo assim, está se referindo a povos que não passaram pelo processo de suas sociedades em classes, não tendo, por este motivo, a necessidade de criar um Estado. Deste modo, a ausência de necessidades não pode ser comparada, e menos ainda igualada, a uma resistência ou a um combate contra a instalação de um Estado nestas sociedades.

Na pesquisa de Clastres chama a atenção a forma negativa como ele se refere ao trabalho. No entendimento apresentado pelo autor, as atividades produtivas realizadas sem um caráter exploratório não são trabalho, pois não são alienadas. ${ }^{7}$ No entanto, o fato de os indígenas da sociedade pesquisada por Clastres dedicarem um tempo consideravelmente limitado à realização de atividades produtivas não significa que eles não se dedicassem ao trabalho, mas que eles trabalhavam pouco, ou apenas o suficiente para suprir suas necessidades energéticas. $O$ tempo destinado ao trabalho pelas pessoas que viviam nas sociedades primitivas de economia baseada na subsistência não passava de quatro horas por dia. Clastres coloca que

Para o homem das sociedades primitivas, a atividade de produção é exactamente medida, delimitada, pelas necessidades a satisfazer, subentendendo-se que se trata essencialmente das necessidades energéticas [...]. Noutros termos, é a vida como natureza que [...] estabelece e determina a quantidade de tempo consagrada a reproduzi-la. O que quer dizer que, uma vez assegurada a satisfação global das necessidades energéticas, nada poderia incitar a sociedade primitiva a desejar produzir mais, isto é, a alienar o seu tempo num trabalho sem destino, uma vez que esse tempo está disponível para a ociosidade, o jogo, a guerra ou a festa (Clastres, 1975: 191).

6 O primeiro capítulo do Manifesto do Partido Comunista começa com a seguinte frase: "A história de todas as sociedades até hoje existentes é a história das lutas de classes" (Marx \& Engels 2005: 40).

7 No entendimento apresentado por Clastres, a atividade produtiva não pode ser considerada trabalho se não for alienada. Segundo o autor, pode-se falar de trabalho "quando a regra igualitária de troca deixa de constituir o'código civil' da sociedade, quando a atividade de produção visa satisfazer as necessidades dos outros, quando à regra de troca se substitui o terror da dívida" (Clastres 1975: 192). 
Entende-se, portanto, que estas sociedades poderiam, se quisessem, aumentar a produção de bens materiais, pois tinham tempo disponível para isso. E poderia acontecer de, sem esforço a mais e sem sobretrabalho, ocorrer a produção de algum excedente, que acabava por ser utilizado em ocasiões consideradas especiais. Por isso que tal sociedade não negava a importância do desenvolvimento tecnológico para as atividades produtivas. No entanto, a utilização de ferramentas mais eficientes não se destinava ao aumento da produtividade, mas à redução do tempo de trabalho para produzir o necessário.

Como já mencionado, Clastres parece querer acentuar uma suposta diferença entre atividade de produção e trabalho, colocando que a primeira consiste em produzir apenas o necessário para sua própria sobrevivência, enquanto trabalho consiste em produzir para garantir a produção da vida de outras pessoas, das pessoas que não trabalham. Dito assim, o autor nega o trabalho como principal atividade humana que diferencia nossa espécie dos demais animais, e atribui ao trabalho produtivo a responsabilidade pela divisão da sociedade em classes, parecendo desconsiderar todos os elementos expostos por estudiosos que se dedicaram a explicar o funcionamento da sociedade capitalista. ${ }^{8}$ A exploração do trabalho não é determinada pelo mero desejo de uns em explorar e pela aceitação da exploração por parte de outros, mas por relações sociais concretas.

Partindo do entendimento provocado pelas análises de Clastres a respeito da inferioridade tecnológica, constrói-se julgamentos que negativam as sociedades primitivas, pois tem-se a tendência de pensar em desenvolvimento tecnológico tomando como referência as necessidades do sistema nos quais se está inserido; no entanto, um equipamento tecnológico precisa apenas dar conta de satisfazer as necessidades da sociedade na qual ele está inserido. É a suposta inferioridade tecnológica das sociedades primitivas que nos leva a crer que elas estejam condenadas à economia de subsistência, quando na verdade não há inferioridade tecnológica, uma vez que suas técnicas acompanham suas necessidades. Segundo Clastres:

Se entendemos por técnica o conjunto de procedimentos de que se dotam os homens, [...] para assegurar um domínio do meio natural adaptado e relativo às suas necessidades, então não podemos mais falar de inferioridade técnica das sociedade primitivas: elas demonstram uma capacidade de satisfazer as suas necessidades pelo menos igual àquela de que se orgulha a sociedade industrial e técnica (Clastres, 1975: 185).

Busca-se aqui explicitar um dos argumentos que normalmente se utiliza para julgar a ausência de mercado nas sociedades primitivas, equivocamente atribuída à inferioridade tecnológica destas sociedades em relação à sociedade capitalista. O próprio Clastres demonstra que não há inferioridade técnica, mas o contrário, destacando que "o rigor de fabricação dos instrumentos da vida quotidiana faz quase de cada instrumento uma obra de arte" (Clastres, 1975: 185). Se existe este rigor técnico e esse forte desenvolvimento das técnicas de fabricação dos instrumentos utilizados como meios de produção, as mulheres destas sociedades poderiam ser mais participantes das atividades de produção, caso tivessem acesso e pudessem utilizar tais instrumentos. No capítulo "O arco e a cesta", fica explícita a relação hierárquica entre homens e mulheres nesta sociedade.

Por ter uma vida econômica baseada principalmente na agricultura e no trabalho com as hortas, Clastres pôde perceber de forma nítida a organização do trabalho baseada na divisão sexual das tarefas. Os homens faziam o trabalho considerado mais pesado, que era preparar o espaço para a instalação da horta, uma tarefa que tomava dois a três meses de ocupação a cada quatro anos. No entanto, quase todo o resto do processo agrícola, da semeadura à colheita, era realizado pelas mulheres, e delas tomava quase todos os dias, não lhes restando tempo para ocupações que lhes proporcionassem prazer sem que fossem obrigação: apenas aos homens sobrava tempo de prazer. Segundo Clastres:

Uma oposição muito nítida organiza e domina a vida quotidiana dos Guayaki: a dos homens e das mulheres cujas atividades respectivas, fortemente marcadas pela divisão sexual das tarefas, constituem dois campos nitidamente separados e aliás, como por todo o lado, complementares (Clastres, 1975: 100).

Por mais que, aparentemente, o trabalho na horta seja realizado de forma complementar, afinal sem a preparação do terreno pelos homens as mulheres não teriam como plantar, e sem o trabalho de plantio realizado pelas mulheres não faria sentido aos homens dedicarem seus tempos à preparação dos terrenos, fica marcada a ideia de incapacidade das mulheres em realizarem tarefas que os homens realizam. Aparentemente esta incapacidade se deve a diferenças físicas e biológicas, mas tal ideia de incapacidades apenas reforça a superioridade de homens sobre as

8 Marx (2013: 255) afirma que "o trabalho é, antes de tudo, um processo entre o homem e a natureza, processo este em que o homem, por sua própria ação, medeia, regula e controla seu metabolismo com a natureza. Ele se confronta com a matéria natural como com uma potência natural. A fim de se apropriar da matéria natural de uma forma útil para sua própria vida, ele põe em movimento as forças naturais pertencentes à sua corporeidade: seus braços e pernas, cabeça e mãos. Agindo sobre a natureza externa e modificando-a por meio desse movimento, ele modifica, ao mesmo tempo, sua própria natureza". 
mulheres. Em relação à forma como a sociedade estudada realiza sua busca por alimentos, Clastres a descreve da seguinte forma:

Poder-se-ia pensar que a procura destas duas classes de alimento [produtos de caça e produtos de coleta] se conforma com o modelo muito espalhado na América do Sul segundo o qual os homens caçam, o que é natural, deixando para as mulheres a tarefa de colectar. Na realidade, as coisas passam-se de maneira muito diferente dado que, entre os Guayaki, os homens caçam e também colectam. Não porque, mais atentos que outros aos lazeres das suas esposas, as queiram dispensar dos trabalhos que normalmente lhes caberiam; mas porque de facto os produtos da colecta são obtidos graças a operações penosas que as mulheres dificilmente poderiam levar a cabo: localização dos enxames, extracção do mel, abate das arvores, etc. Trata-se portanto dum tipo de colecta que cabe bem melhor dentro do quadro das actividades masculinas. (CLASTRES, 1975: 101).

Entende-se, portanto, que Clastres naturaliza a divisão sexual do trabalho, pois, para ele, é natural que os homens se dediquem à caça, e que as mulheres se dediquem à coleta. Além disso, ao definir que determinadas tarefas seriam mais dificultosas para as mulheres do que para os homens, Clastres está dizendo que os corpos femininos são naturalmente menos capazes do que os corpos masculinos para a realização destas tarefas. Contudo, a divisão sexual do trabalho não ocorre de forma natural, pois sim, trata-se de um processo extremamente artificial que tem por objetivo separar homens e mulheres entre superiores e inferiores, independentemente das características físicas de cada indivíduo de cada um dos gêneros. ${ }^{9}$ Se já foi exaltada a qualidade do desenvolvimento técnico dos povos primitivos no sentido de facilitar o trabalho produtivo, o que impede as mulheres destes povos a terem acesso às ferramentas necessárias para torná-las tão capazes quanto os homens de extrair mel, de modo que as tarefas deixem de ser enquadradas como masculinas ou femininas?

A divisão sexual do trabalho em Clastres não se refere meramente a um complemento na repartição das tarefas, baseada nas capacidades biológicas de cada gênero, mas a uma relação hierárquica, nas quais as tarefas realizadas pelos homens são consideradas mais importantes do que aquelas realizadas pelas mulheres. ${ }^{10}$ Essa divisão, que em Clastres aparece como uma espécie de status, que coloca homens em sobreposição a mulheres, encontra em Engels uma explicação a partir das condições materiais. Engels parte da compreensão de que "o fator decisivo da história é, em última instância, a produção e a reprodução da vida imediata", que condiciona a ordem social em que vivem homens e mulheres de determinada época "pelo grau de desenvolvimento do trabalho, de um lado, e da família, do outro" (ENGELS, 2002: 7-8). Neste caso, a compreensão da divisão das tarefas ou mesmo do papel social atribuído a homens e mulheres não encontra sua explicação apenas em condições biológicos, mas fundamentalmente nas relações concretas de produção e reprodução.

\section{CONSIDERAÇÕES FINAIS}

O presente artigo procurou discutir teoricamente o conceito de divisão sexual do trabalho, a partir das contribuições de Engels e Clastres. Em um primeiro momento mostrou-se como esse fenômeno está presente na sociedade brasileira contemporânea, a partir de dados apresentados pelo IBGE acerca da situação de trabalho das mulheres, mostrando que, apesar do processo de industrialização e de reorganização do trabalho, a maior parte do trabalho doméstico ainda é realizado pelas mulheres, em jornadas duplas ou triplas, ou que os salários em média são inferiores apesar de as mulheres apresentarem uma escolaridade superior à dos homens. Neste texto procura-se desenvolver alguns apontamentos iniciais sobre a dinâmica histórica do seu processo de exploração. Com isso pode-se compreender não apenas a dinâmica do seu processo de opressão como as formas de superá-lo.

Pretendeu-se discutir diferentes abordagens do conceito de divisão sexual do trabalho, a partir de dois estudos clássicos das Ciências Sociais, um escrito por Friedrich Engels, e o outro por Pierre Clastres. O estudo de Pierre Clastres, publicado na segunda metade do século XX, procura dialogar com as ideias desenvolvidas por Friedrich Engels no final do século XIX, tentando se contrapor a algumas de suas principais teorias, como a origem do Estado e a relação desse processo com a propriedade privada. No presente artigo procurou-se demonstrar como cada um destes dois autores clássicos discutem a questão do trabalho e seu papel na sociedade, disso desdobrando as com-

9 Na década de 1930, a antropóloga Margareth Mead publicou um estudo no qual descreve as diferentes organizações sociais em três sociedade primitivas por ela observadas (Arapesh, Mundugumor e Tchambuli). Em relação aos padrões comportamentais que os europeus estabelecem para os indivíduos de cada sexo, e suas experiências nos três grupos observados, Mead (2000: 10) apresenta a seguinte observação: "Numa delas, homens e mulheres agiam como esperamos que as mulheres hajam: de um suave modo parental e sensível; na segunda, ambos agiam como esperamos que os homens ajam: com bravia iniciativa; e na terceira, os homens agem segundo o nosso estereótipo para mulheres, são fingidos, usam cachos e vão às compras, enquanto as mulheres são enérgicas, administradoras, parceiros desadornados". Neste estudo, as observações de Mead vão além dos comportamentos dos indivíduos, chegando à forma como o trabalho dos grupos investigados é dividido com base no sexo. A autora coloca que "apesar dos Tchambuli serem patrilineares em sua organização, [...] são as mulheres, entre os Tchambuli, que detém a verdadeira posição de poder na sociedade. [...] Quanto à alimentação, o povo depende da pesca das mulheres" (Mead 2000: 246).

10 Embora não diga diretamente que sua análise parte de diferenças biológicas entre homens e mulheres, Clastres provoca este entendimento ao explicar a divisão do trabalho (que ele chama de tarefas), "[...] segundo o qual os homens caçam, o que é natural, deixando para as mulheres a tarefa de colectar. Na realidade, as coisas passam-se de maneira muito diferente dado que, entre os Guayaki, os homens caçam e também colectam. Não porque, mais atentos que outros aos lazeres das suas esposas, as queiram dispensar dos trabalhos que normalmente lhes caberiam; mas porque de facto os produtos da colecta são obtidos graças a operações penosas que as mulheres dificilmente poderiam levar a cabo: localização dos enxames, extracção do mel, abate das arvores, etc. Trata-se portanto dum tipo de colecta que cabe bem melhor dentro do quadro das actividades masculinas" (Clastres 1975: 101) 
preensões tanto de Engels quanto de Clastres a respeito da divisão do trabalho e como essa forma de organização social atravessa a relação entre homens e mulheres.

Com o estudo aqui realizado, procurou-se demonstrar que o conceito de divisão sexual do trabalho é entendido por Clastres de forma naturalizada, baseada em relações biológicas, enquanto Engels entende o mesmo como um tipo de relação social sobre o qual se baseia o desenvolvimento do capitalismo. Engels, ao embasar sua perspectiva no materialismo histórico, consegue demonstrar a divisão sexual do trabalho como um processo histórico enraizado nas relações concretas estabelecidas pelos sujeitos de diferentes sociedades ao longo da história.

\section{REFERÊNCIAS}

Antunes, Ricardo. (2009) Os sentidos do trabalho: ensaio sobre a afirmação e a negação do trabalho. $2^{a}$ edição. Campinas, SP: Autores Associados.

Clastres, Pierre. (1975) A Sociedade contra o Estado: investigações de Antropologia Política. Porto: Editora Afrontamento.

Engels, Friedrich. (2002) A origem da família, da propriedade privada e do Estado. São Paulo: Centauro.

Hirata, Helena. (2002) Nova divisão sexual do trabalho: um olhar voltado para a empresa e a sociedade. São Paulo: Boitempo.

IBGE. (2018) Estatísticas de gênero: indicadores sociais das mulheres no Brasil. Estudos e Pesquisas: informação demográfica e socioeconômica. Número 38.

Kergoat, Danièle. (2009) Divisão sexual do trabalho e relações sociais de sexo. In: HIRATA, Helena (org.). Dicionário crítico do feminismo. São Paulo: UNESP.

Marx, Karl. (2004) Capítulo VI inédito de O capital. $2^{a}$ edição. São Paulo: Centauro.

Marx, Karl. (2013) ○ Capital: crítica da economia política. Livro I. São Paulo: Boitempo.

Marx, Karl; ENGELS, Friedrich. (2005) Manifesto comunista. São Paulo: Boitempo.

Mead, Margareth. (2000) Sexo e temperamento. $4^{a}$ edição. São Paulo: Perspectiva.

Toledo, Cecília. (2017) Gênero e classe. São Paulo: Sundermann.

How to cite this article: Silveira dos Santos Rosa, M. (2020). Da divisão sexual do trabalho à naturalização da opressão: um estudo acerca das obras de Engels e Clastres. Religación. Revista De Ciencias Sociales Y Humanidades, 5(23), 31-39. Recuperado de http://revista.religacion.com/index.php/religacion/article/view/593

Submitted: 03 January 2020 Accepted: 15 March 2020 Published: 31 March 2020

Religación. Revistais de Ciencias Sociales y Humanidades is a peer-reviewed open access journal published by CICSH-AL Centro de Investigaciones en Ciencias Sociales y Humanidades desde América Latina |Religación| 